\title{
A Study of Management of Benign Lesions of the Larynx
}

\author{
${ }^{1}$ Pankaj Kumar Doloi, ${ }^{2}$ Swagata Khanna \\ ${ }^{1}$ Senior Resident, Department of ENT, Gauhati Medical College and Hospital, Guwahati, Assam, India \\ ${ }^{2}$ Professor, Department of ENT, Gauhati Medical College and Hospital, Guwahati, Assam, India
}

Correspondence: Pankaj Kumar Doloi, Senior Resident, Department of ENT, Head, Neck and Cosmetology Clinic, Swagat Endolaparoscopic Surgical Research Institute, AT Road, Shantipur, Guwahati-781009, Assam, Phone: 094011-54028, Fax: 03612519026, e-mail: doloi.pankaj@gmail.com

\begin{abstract}
A two-year prospective study was conducted from J une 2008 to May 2010. A total of 80 patients with benign laryngeal lesions were included in the study based on symptoms, such as hoarseness of voice, foreign body sensation, vocal fatigue, dyspnea and cough and with positive clinical findings on indirect laryngoscopy. Diagnostic and therapeutic laryngoscopic and microlarygoscopic procedures were employed. Vocal cord polyps were observed to be the commonest type of lesions. Out of the 80 patients in the study group, $40 \%$ patients got complete relief with voice rest and vocal rehabilitation; $60 \%$ patients required surgery, which included endoscopic/microlarygoscopic endolaryngeal surgery and external approaches. There was no recurrence in cases of vocal polyps and nodules during the period of observation. Endolaryngeal surgery and voice rest offer a cost-effective, useful and safe method for the management of benign laryngeal lesions. With the inclusion of lasers, they can be more precisely operated. As such, the standard treatment of choice in all types of benign tumors of the larynx should consist of a triad of approach by microlaryngeal surgery (either microscopic or endoscopic, with or without use of lasers), voice rest and vocal rehabilitation.
\end{abstract}

Keywords: Benign lesions, Larynx.

\section{INTRODUCTION}

A benign lesion of the larynx was defined by $\mathrm{Hollinger} \mathrm{(1951)}$ as any mass of tissue in the larynx which does not present characteristics of malignancy. ${ }^{1}$ The significance of benign lesions lies in the importance of its function in speaking and the contribution of voice to one's own identity. The benign laryngeal lesions occur in a ratio of 2:3 to the malignant lesions. $V$ arious studies opined that true benign neoplastic lesions are uncommon and occur in a ratio of 1:6 to the non-neoplastic lesions.

The study is important for the laryngologist not only for the symptoms they produce but also because of the necessity of distinguishing them from malignant lesions. Some of these tumors may even undergo malignant changes like papilloma (4\%), granular cell tumor ( $2 \%$ ). ${ }^{2,3} \mathrm{~N}$ on-neoplastic lesions seem to be caused primarily by vibratory trauma (excessive voice abuse). Cigarette smoking, infection, allergy and gastric reflex are cofactors. Small lesions can be excised endoscopically by $\mathrm{CO}_{2}$ laser or by microlaryngeal instruments. Larger lesions extending beyond laryngeal framework often require pharyngotomy or laryngofissure.

\section{AIM}

To analyze age, sex distribution and symptomatology, site of involvement and the prognosis of the common types of benign lesions of larynx.

\section{MATERIALS AND METHODS}

This study was a two-year prospective study from 1st] une 2008 to 30th M ay 2010 carried out at D epartment of ENT, Gauhati M edical College, Guwahati, A ssam. Patients were selected based on symptoms, such as hoarseness of voice, vocal fatigue, foreign body sensation, respiratory distress, cough and their duration with positive clinical findings on indirect laryngoscopy (Table 1). The patients were in the age group of 5 to 65 years. A Il nonoperative and malignant cases were excluded. A ge, sex, occupation and personal history like smoking, tobacco and alcohol were taken. A Il infective, mal ignant and speech defect due to CNS lesions were excluded. Diagnostic hematological, radiological and laryngoscopic investigations were done. Treatment advised was either conservative medical/speech therapy and /or surgical therapy. Conservative medical therapy included antibiotics, anti-inflammatory, steam inhalation and voice rest. Surgical procedures include tracheostomy, pharyngotomy, laryngoscopic procedures under LA and microlaryngoscopic procedures under GA . All excised tissues

\begin{tabular}{lcc} 
Table 1: Incidence of the symptoms \\
\hline Symptoms & No. of cases & Percentage \\
\hline Hoarseness & 76 & $95 \%$ \\
Vocal fatigue & 42 & $52.5 \%$ \\
Cough & 24 & $30 \%$ \\
Dyspnea & 8 & $10 \%$ \\
Foreign body sensation & 6 & $7.5 \%$ \\
\hline
\end{tabular}


were sent for histopathological examination. Postoperative management includes complete voice rest for two weeks followed by gradual talking.

\section{RESULTS AND OBSERVATIONS}

A total of 80 patients were studied during this period. Y oungest patient was 5 years of age and oldest 65 years of age. M ajority of the patients were in the age group of 21 to 30 years. M ales were seen to predominate over females with a ratio of $4: 1$ (i.e. 64 males and 16 females). Most of the patients in our study presented with hoarseness ( $95 \%$ ). D uration of symptoms ranged from 15 days to 1.5 years. M ost of the cases (40\%) were diagnosed by indirect laryngoscopy during routine ENT examination and rest were diagnosed by direct laryngoscopic $(40 \%)$ and videolaryngoscopic procedures (17.5\%). Incidence of vocal polyp was $37.5 \%$ (Fig. 1) followed by vocal nodule 27.5\% (Fig. 2), multiple laryngeal papillomatosis 10\% (Fig. 3), hemangioma $10 \%$, epiglottic cyst $5 \%$, vocal cord cyst $7.5 \%$ and intubation granuloma $2.5 \%$. Most common site of involvement was true vocal cord $83.33 \%$. Vocal polyps were mainly treated by excision under direct laryngoscopy (73\%), while $90 \%$ of the vocal nodules responded to conservative therapy (Table 2). One patient with epiglottic cyst was treated by suprahyoid pharyngectomy.

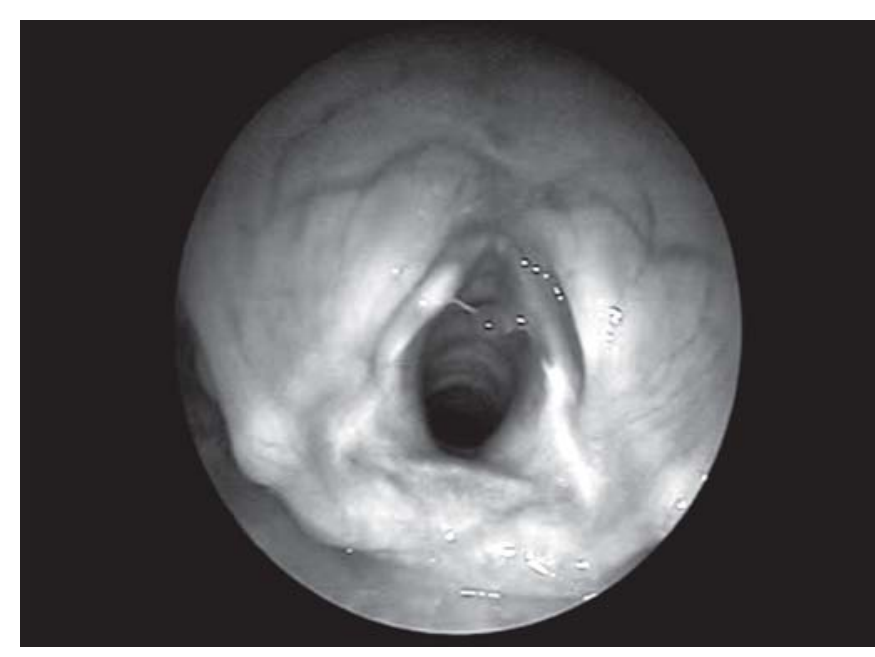

Fig. 1: Vocal cord polyp

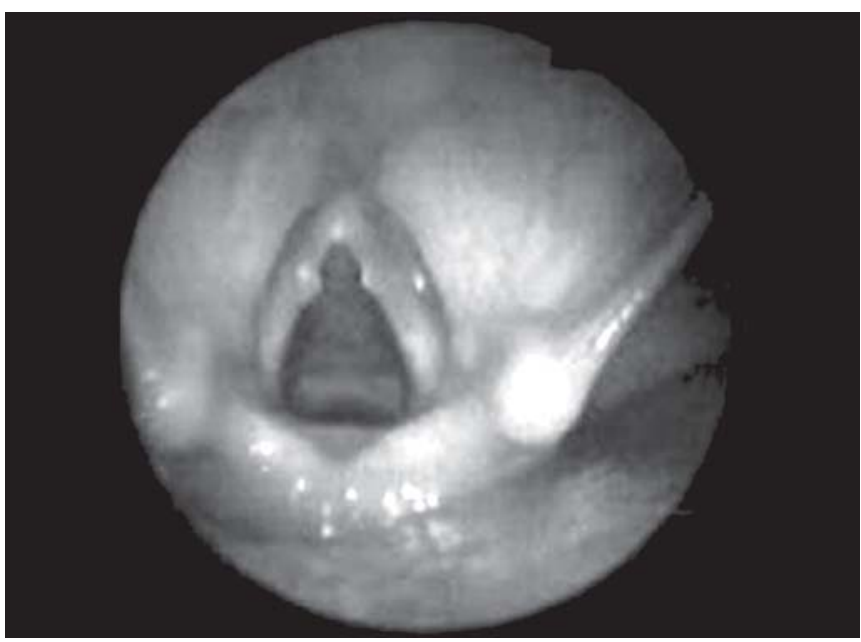

Fig. 2: Vocal nodules

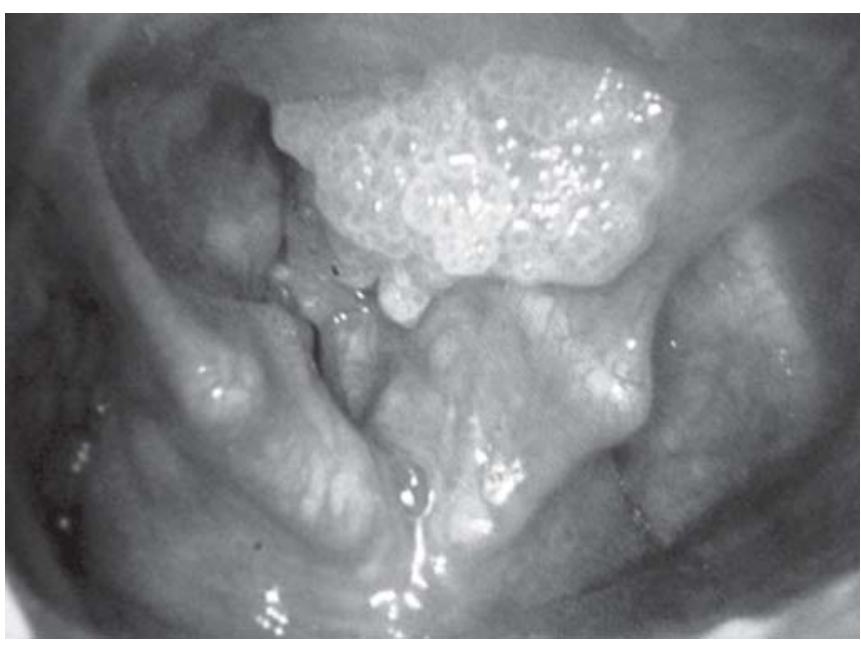

Fig. 3: Multiple papilloma larynx

\section{PROGNOSIS}

M aximum cases were totally symptom free except three cases of multiple laryngeal papillomatosis who were treated in multiple sittings.

\section{DISCUSSION}

The definition of benign lesions of the larynx requires some elaboration. In 1938, $\mathrm{N}$ ew and Erich published the M ayo Clinic

Table 2: Management of various types of lesions

\begin{tabular}{|c|c|c|c|c|c|c|}
\hline \multirow[t]{2}{*}{ Type of lesion } & \multicolumn{2}{|c|}{ Conservative } & \multicolumn{3}{|c|}{ Surgery } & \multirow[t]{2}{*}{ Total (\%) } \\
\hline & $\begin{array}{l}\text { Conservative } \\
\text { alone }\end{array}$ & $\begin{array}{l}\text { Conservative + } \\
\text { voice therapy }\end{array}$ & Excision by $D L$ & $\begin{array}{l}\text { Excision by } \\
\text { endoscopy }\end{array}$ & $\begin{array}{l}\text { External } \\
\text { approach }\end{array}$ & \\
\hline VC polyp & 0 & 4 & 22 & 4 & 0 & $30(37.5 \%)$ \\
\hline VC nodule & 6 & 14 & 2 & 0 & 0 & $22(27.5 \%)$ \\
\hline VC cyst & 0 & 4 & 2 & 0 & 0 & $6(7.5 \%)$ \\
\hline VC hemangioma & 0 & 2 & 4 & 2 & 0 & $8(10 \%)$ \\
\hline MLP & 0 & 0 & 0 & 8 & 0 & $8(10 \%)$ \\
\hline Epiglottic cyst & 0 & 0 & 2 & 0 & 2 & $4(5 \%)$ \\
\hline Intubation granuloma & 0 & 2 & 0 & 0 & 0 & $2(2.5 \%)$ \\
\hline Total & $6(7.5 \%)$ & $26(32.5 \%)$ & $32(40 \%)$ & $14(17.5 \%)$ & $2(2.5 \%)$ & $80(100 \%)$ \\
\hline
\end{tabular}


experience of 722 patients presenting with benign laryngeal pathology. They proposed that as true proliferative neoplasms were often clinically indistinguishable from nonproliferative inflammatory or hyperplastic growths, the term benign tumor should be used to encompass all abnormal growth of tissue in the larynx that lacked malignant or metastatic properties. Since then, some authors have revised the concept, classifying vocal fold nodules, polyps, cyst and nonspecific granulomas to be mucosal reactive inflammatory disorders and therefore nonneoplastic in nature. N otwithstanding the various view points, the principles of management remain analogous. The presence of mass lesion in the larynx can provoke numerous acute, chronic, progressive or even life-threatening symptoms. When assessing the patient with a potential laryngeal lesion, a thorough history should be taken with particular emphasis on the age of the patient, the temporal course of the symptoms complex, the presence of infection, any previous surgery or trauma, and presence or absence of respiratory, vocal or swallowing symptoms. Although the experienced laryngologist may be able to make an accurate clinical diagnosis even by indirect laryngoscopy in the outpatient clinic, evidence suggest that the accuracy of diagnosis based on visual examination alone is subject to some variation.

The first line of treatment for lesions caused by phonotrauma is behavioral intervention with speaking and singing therapy. The primary goal of voice therapy is to maximize efficiency of phonation and to eliminate maladaptive vocal behaviors that exacerbate these masses. A dditionally, patients shoul d be treated for concomitant problems that contribute to mucosal friability, such as laryngopharyngeal reflux and poor vocal hygiene. When maximal behavior intervention does not achieve satisfactory improvements in voice, surgical treatment is considered. The decision to pursue surgical interventions; however, should take into account multiple factors, including the patient's vocal impairment, type and location of the lesion, and willingness to accept surgical risk. Patients who do not have significant functional impairment from their lesions may not need surgical intervention. The overall goal of surgical intervention for benign lesions is careful removal of abnormal tissue giving maximum respect to the normal superficial lamina propria. Significant improvement in laryngeal endoscopic microsurgical understanding, technique and instrumentation has occurred over the past three decades, and the refinement is still continuing. It has brought a new era for diagnosis and treatment of benign lesions of larynx with maximum accuracy and safety.

The results in our series were in concurrence with most of the review ed literature. A male: female ratio of 4:1 was observed in this study which is similar to the study by StewartJ P (1957), Chopra et al (1997) and B atra et al (2004) who also showed male preponderance. ${ }^{4-6}$ The commonest age group of presentation was 21 to 40 years which is consi dered as the most active period of life. Our observation is supported by Stewart JP (1957), Hegde M C (2005) and Singhal P (2009) who also reported maximum number of the patient in the age group of 20 to 40 years. ${ }^{7,8}$ M ost common occupation of suffering was imams of mosque and naamghar (temple) singers which are housewives in a study by Singhal P (2009). Most common presenting feature was hoarseness of voice $(95 \%)$ which is similar to all other studies. ${ }^{4-6}$ Duration of symptoms ranged from 1 month to 18 months in our study and $72.5 \%$ had duration of symptoms in months. Chopra and K apoor (1997) have noted $68.65 \%$ patients with duration of symptoms less than 1 year. ${ }^{5}$

While studying, $32(40 \%)$ patients were subjected for direct laryngoscopy and 14 (17.5\%) for videolaryngoscopy. In a study by Parikh et al, $60 \%$ of the patients underwent microlaryngoscopy and in another study by Baitha et al DL/M LS was done in $36.36 \%$ of the patients. ${ }^{9,10}$ Neoplastic tumor in our study was $20 \%$ which is $14 \%$ by Shaw et al and $24.3 \%$ by Stewart J $P$. $\mathrm{N}$ ew and E rich reported around 210 such tumors in a series of 722 patients presenting over 30 years period. A mong them, 194 were squamous papillomas. Hollinger and Johnstone reported a similar series collected over 15 years. They reported 125 true benign tumors, of which 115 (92\%) were papillomas. ${ }^{1}$ Most common non-neoplastic lesion in our study was vocal polyp $37.5 \%$ which is $71.2 \%$ by Shaw et al, $68.3 \%$ by Kambic et al and $16 \%$ by Chopra et al. ${ }^{11} \mathrm{M}$ ost common site in our study was true vocal cord (85\%) which is similar to the different studies by $\mathrm{Hegde}$ et al (2005) and Singhal et al (2009) respectively.

Surgery was the prime mode of treatment in our study (60\%) which is supported by Singhal et al $(94 \%)$ and Hegde et al (83.29\%). Endoscopic excision was done in $17.5 \%$ of the patients in our study. Contrary to this, Chopra and Kapoor (1997) reported the incidence of benign glottic lesions undergoing microlaryngeal surgery to be $73.14 \%$ and Saxena and $\mathrm{G}$ ode (1975) to be $58 \%$. B oth these studies involve a limited group of patients in whom focus of attention is microsurgery of larynx which is not the case with our study. V oice rest and speech therapy cured $40 \%$ of the patients in this study which is only $6 \%$ by Singhal et al. It is probably due to the early detection of benign lesions in our study.

\section{CONCLUSION}

The symptoms of benign laryngeal lesions may vary from mild hoarseness to stridor. Early diagnosis can lead to effective management and good recovery from the disease. Early diagnosis also leads to identification of malignancy in early stages and better prognosis. Standard treatment of choice should be microlaryngeal surgery (microscopic/endoscopic) with or without laser, voice rest and speech rehabilitation.

\section{REFERENCES}

1. Hollinger $\mathrm{PH}$, J ohnston $\mathrm{KC}$. B enign tumors of the larynx. A nn Otol 1951;60:496-509.

2. Winston P, Epstein SS. Papilloma of the larynx: A clinicopathological study. J Laryngol Otol 1958;72:452-64.

3. Satal off RT, R essue J C, Portell M, H arris RM , O ssoff R, M erati $A L$, et al. Granular cell tumors of the larynx. J Voice Mar 2000;14(1):119-34. 
4. Stewart JP. The histopathology of benign tumors of the larynx. J Laryngol Otol 1957;71:718-29.

5. Chopra H, Kapoor M. Study of benign glottic lesions undergoing microlaryngeal surgery. Indian J ournal of Otolaryngology and Head and Neck Surgery 1997;49(3):276-79.

6. Batra K, M otwani A ni G, Sagar PC. Functional voice disorders and their occurrence in 100 patients of hoarseness as seen in oil fibreoptic laryngoscopy. Indian J Otolaryngol Head and Neck Surgery 2004;56(21):91-95.

7. Hegde M C, K amath PM, B hojwani K, Peter R, Babu PR. B enign lesions of the larynx: A clinical study. IJ L 0 2005;57(1):35-38.
8. Singhal $P, B$ handari $A$, Chouhan $M$, Sharma M P, Sharma $S$. Benign tumors of the larynx: A clinical study of 50 cases. IJ L 0 2009;61(1):26-30.

9. Nimish Parik. A etiology study of 100 cases of hoarseness of voice. Indian Journal of Otolaryngology and Head and Neck surgery. 91 J une 43(2):71-73.

10. Baitha Sambu, Raizada R M , Singh K ennedy A K, Puttewar M P, Chaturvedi V N. Clinical profile of hoarseness of voice. Ind J Otolaryngol Head Neck Surg J an-M arch 2002;54(1):14-18.

11. Kambic V, Radsel Z, Zargi M, Acko M. Vocal cord polyps: Incidence, histology and pathogenesis. J Laryngol Otology 1981;95:609-18. 